\title{
Petrole Bağımlı Ülkelerde Petrol Fiyatlarının Sanayi Üretimine Etkisi: Panel Nedensellik Çalışması
}

\author{
Effect of The Oil Prices on The Industrial Production In Oil-Dependent \\ Countries: Panel Cointegration Application
}

\author{
Hilal GÜNDOĞAN ${ }^{1}$ \\ Dilek TOK ${ }^{2}$
}

\section{ÖZET}

Petrol ülkelerin ekonomik kalkınma ve gelişmelerinde önemli bir unsurdur. Enerji kaynakları içinde petrol gibi yenilenemez enerji kaynaklarının sanayi üretiminde kullanılması petrol fiyatlarındaki değişikliklerden etkilenilmesi anlamına gelmektedir. $\mathrm{Bu}$ amaçla petrole bağımlı olan ülkelerde petrol fiyatlarındaki değişimin yine bu ülkelerin sanayi üretimleri üzerindeki etkisi araştırılmıştır. 2000-2015 yılları arası çeyreklik veriler kullanılan çalışmada en çok petrol ithal eden 15 ülkenin sanayi üretim endeksleri ile ham petrol varil fiyatı arasındaki uzun dönemli ilişki Pedroni (1999), Kao (1999) ve Johanser Fisher eşbütünleşme analizi yardımıyla incelenmiştir. Bu iki değişken arasında uzun dönemde istatistiksel olarak anlamlı ve pozitif ilişki olduğu görülmüştür. Daha sonra sanayi üretim endeksi ve ham petrol varil fiyatı arasındaki uzun dönemli ilişkiyle ilgili çıkarımda bulunabilmek için düzenlenmiş/geliştirilmiş en küçük kareler yöntemi (Fully Modified Ordinary Least Squares-FMOLS) ve dinamik en küçük kareler yöntemi (Dynamic Ordinary Least Square-DOLS) uygulanmış ve katsayı her iki yöntemde de 0.47 olarak tahmin edilmiştir.

Anahtar Kelimeler: Petrol fiyatı, ekonomikbüyüme, sanayi üretim endeksi, panel eşbütünleşme

\section{GíRiş}

Tarihte yaşanan petrol krizleri incelendiğinde petrol fiyatlarında yaşanan şokun öncelikle tüketim ve yatırım mallarına olan talebi azaltması yolu ile ülke gelirini etkilediği görülmektedir (Hamilton,1988). Bunun yanı sıra petrol imalat sanayiinde hem üretim girdisi hem de enerji kaynağı olarak önemli girdilerdendir. Buna https://orcid.org/0000-0002-9183-4865

https://orcid.org/0000-0002-7432-5428

\begin{abstract}
Petroleum is an important source of economic growth and development. Used in the industrial production of non-renewable energy sources like oil in the energy supply it means to be influenced by changes in oil prices. The purpose is to investigate the impact on the oil-dependent country's industrial production changes in oil prices. Long-term relationship between crude oil price per barrel and industrial production index of the most oil-importing 15 countries is analyzed by Pedroni(1999), Kao(1999) and Johanser Fisher cointegration tests. Quarterly data from 2000-2015 is used in the study and the long term relationship between these two variables is found that is statistically significant and positive. Then FMOLS and DOLS methods is applied for inference about the long-term relationship between crude oil price for barrel and industrial production index and coefficients are estimated to be at 0.47 in both methods.
\end{abstract}

Keywords: Oil price, economic growth, the industrial production index, panel cointegration

bağlı olarak petrol talebi her geçen gün artarken petrol arzının sınırlı olması gelecekte petrol fiyatlarının artması sonucunu doğurmaktadır. Petrol fiyatlarının artması petrol ithal eden ülkelerde döviz rezervlerinin azalması yoluyla ülkelerin cari işlemler dengesini etkilediği gibi önemli bir maliyet unsuru olmasından dolayı reel sektörü de büyük ölçüde etkilemektedir. 
Petrol fiyatındaki değişim petrol ithal eden ve ihraç eden ülkelerde farklı sonuçlar ortaya çıkarmaktadır. Petrol fiyatlarındaki artış petrol ihraç eden ülkelerde döviz gelirini artırarak, reel gelir düzeyini yükseltmekte cari işlemler fazlası oluşturmaktadır (Yanar, 2014:1012). Petrol fiyatlarındaki artış petrol bağımlıı̆ı yüksek ithalatçı ülkelerde ise girdi maliyetini artırarak fiyatları yükseltmekte, döviz rezervlerini azaltmakta, cari açığı artırarak reel gelirleri azaltmaktadır. Özellikle Türkiye gibi cari açıklarını borçlanarak kapatan ülkelerde petrol fiyat artışı makroekonomik istikrarsızlık doğurabilmektedir. Petrol fiyatları arttığında petrol ihraç eden ülkelerin ise reel gelirleri artmaktadır. Dolayısıyla petrol fiyatlarındaki artış petrol ithal eden ülkelerden petrol ihraç eden ülkelere doğru gelir transferine yol açarak uluslararası gelir dağılımı adaletsizliğinin artmasına neden olmaktadır (Iwayemi ve Fowowe,2011:603).

Petrol fiyatlarındaki değişikliğin petrol bağımlılığı yüksek ülkelerin üretimlerinde ve dolayısıyla reel gelirlerinde önemli değişiklik yaratmasını önlemek için petrole alternatif enerji kaynaklarına yönelmesi, petrole bağımlılık düzeylerinin düşürülmesi gerekmektedir.

Ham petrol fiyatlarının artması petrol ithalatı yapan ülkelerde üretim maliyetlerini artırarak maliyet enflasyonu yaratmaktadır. Üretim maliyeti artan firmalar bunu satış fiyatına yansıtmakta bu durum tüketici refahını olumsuz yönde etkilemektedir (Özdemir ve Akgül,2015:367). Petrol gibi endüstriyel üretimde önemli bir girdinin fiyatında meydana gelen değişim sanayi üretimini doğrudan etkilemektedir.

Çalışmamızda en çok petrol ithal eden 15 ülkede petrol fiyatlarındaki değişimin yine bu ülkelerin sanayi üretimleri üzerindeki etkisi panel eşbütünleşme yöntemleriyle incelenmiştir. Daha sonra sanayi üretim endeksi ve ham petrol varil fiyatı arasındaki uzun dönemli ilişkiyle ilgili çıkarımda bulunabilmek için FMOLS ve DOLS yönetimi uygulanmıştır.

\section{LITERATÜR ÖZETI}

Petrol fiyatları ile genel makroekonomik görünüm arasındaki ilişkiyi İkinci Dünya Savaşından OPEC krizine kadar inceleyen Hamilton (1983), 1948-72 döneminde Amerikan ekonomisinde yaşanan resesyonla petrol şokları arasında anlamlı bir ilişki gözlemlemiştir. Hamilton (1983) ayrıca OPEC sonrası ekonomilerin çoğunun da petrol fiyatlarındaki artıştan etkileneceğini dile getirmiştir.

Hamilton (1983) çalışmasında petrol fiyatları ile altı temel makroekonomik değişken arasındaki ilişkiyi Granger nedensellik analiziyle incelemiş ve 1948-72 dönemi için petrol fiyatları ile reel GSMH ve işsizlik arasında ilişkiye rastlamıştır. Daha sonra Mork (1989) tarafından yapılan çalışmada da Hamilton (1983)'a atıfta bulunulmuş ve petrol fiyatları ile ekonomik performans arasında asimetrik ilişki olduğu sonucuna varılmıştır. Hooker (1996) ise çalışmasında Hamilton (1983) ve Mork (1989)'a atıfta bulunarak petrol fiyatları ile makroekonomik performans arasında anlamlı bir ilişki olmadığını ileri sürmüştür. Ancak 1986 yılından bu yana petrol fiyatlarındaki artış devamında reel gelirde gözlemlenen azalışlar Mork (1989)'un çalışmasını doğrular nitelikte değildir (Hamilton,1996). Hamilton (1996) çalışmasında petrol şoklarının talebi etkileyerek makroekonomik değişkenleri etkilemekte olduğunu belirtmektedir. Hamilton (1996) petrol fiyatlarındaki artışın makroekonomiyi negatif etkilerken; petrol fiyatlarındaki azalışın makroekonomiyi pozitif yönde etkilediğini dile getirmiştir.

Petrol fiyatlarındaki dalgalanma ile makroekonomik performans arasındaki ilişkiyi inceleyen diğer bir çalışma Ferderer (1990) tarafından yapılmıştır. Ferderer (1990) çalışmasında Amerikan ekonomisinde petrol fiyatlarındaki değişme ile reel GSMH arasında asimetrik bir ilişki olduğu sonucuna varmıştır.

Burbidge ve Harrison (1984) petrol fiyat artışlarının etkilerini 1961-1982 döneminde OECD üyesi 5 ülke (ABD, Japonya, İngiltere, Almanya, Kanada) için yedi değişkenli VAR modeli ile analiz etmiştir. Petrol fiyatlarında yaşanan şokun değişkenler üzerindeki etkisi etki-tepki fonksiyonlarıyla incelenmiş ve 1973 petrol krizi sonrası petrol fiyatlarında yaşanan artışın endüstriyel üretimde düşüşe neden olduğu sonucuna varmıştır. Petrol fiyatlarının endüstriyel üretim üzerindeki etkisi ABD ve İngiltere'de fazlayken; Japonya, Almanya ve Kanada'da daha az olduğu gözlemlenmiştir.

Cunado ve Gracia (2003) çalışmalarında 1960-1999 çeyrek dönemlik verilerle 15 Avrupa ülkesinde petrol fiyatındaki değişikliğin enflasyon ve sanayi üretimi üzerindeki etkilerini yapısal kırılmalı eş bütünleşme testiyle analiz etmişlerdir. Çalışma petrol fiyatındaki değişikliğin enflasyon üzerinde önemli bir etkisinin olmadığını gösterirken; sanayi üretiminde ters yönlü etki ortaya çıkardığını göstermiştir. Ayrıca petrol fiyatı şoklarına ülkelerin verdikleri tepkilerin önemli farklılık gösterdiği gözlemlenmiştir. Cunado ve Gracia (2004) makalelerinde ise 1975-2002 döneminde 6 Asya ülkesi için petrol fiyatlarında meydana gelen 
değişikliğin ekonomik faaliyetler ve tüketici indeksleri üzerindeki etkisini incelemiştir. Petrol fiyatlarındaki değişikliğin ekonomik faaliyetler üzerindeki etkisi kısa dönemde sınırlı olup; uzun dönemde petrol fiyatlarındaki değişiklik ile ekonomik faaliyetler arasında ilişki olmadığı sonucuna ulaşmışlardır. Petrol fiyatlarındaki değişikliğin analiz edilen ülkelerde tüketici fiyat indeksleri üzerindeyse önemli bir etkiye sahip olduğu sonucuna varmışlardır. Çalışmaya göre petrol fiyatlarındaki değişikliğin ekonomik faaliyetler üzerindeki etkisinin de petrol ithal eden ve ihraç eden ülkelere göre değişebileceğini bu bakımdan genişletilmiş bir analizin yapılması gerektiğini ve tek bir sonuca ulaşmanın mümkün olmadığı belirtilmiştir.

Lee ve Ni (2002), VAR modeli yardımıyla farklı endüstrilerde petrol fiyatındaki değişikliklerin etkisi araştırıımıştır. Ele alınan endüstriler içinde petrol girdisini yoğun kullanan endüstrilerde petrol fiyatındaki değişiklik arzı etkilerken diğer endüstrilerde (petrol girdisini yoğun olarak kullanmayan) petrol fiyatındaki değişiklik talebi etkilemektedir. Örneğin petrol rafinerisi ve endüstriyel kimyasal endüstrilerinde petrol fiyatındaki değişiklik arzı etkilemekteyken; otomotiv endüstrisinde talebi etkilemektedir.

Abeysinghe (2001), VARX yöntemi kullanarak 19822000 döneminde 12 ülkenin GSYiH büyümesinde petrol fiyatlarının dolaylı ve doğrudan etkilerini araştırmıştır. Alınan 12 ülke ASEAN4 (Endonezya, Malezya, Filipinler ve Tayland), NIE4 (Hong Kong, Güney Kore, Singapur ve Tayvan), Çin, Japonya, ABD ve OECD ülkelerinin kalanını bir grup olarak ele almıştır. Malezya ve Endonezya net petrol ihracatçısı iken diğer ülkeler net petrol ithalatçısıdır ayrıca Singapur Malezya ve Endonezya'nın ticaret ortağıdır. Çin petrol üreticisi olmasına karşın net petrol ithalatçısıdır bu bakımdan Çin'in petrol fiyatındaki artıştan negatif etkisi diğer petrol ithalatçısı ülkelerden daha azdır. Petrol fiyatındaki artış petrol ithal eden ülkelerin GSYiH büyümesini negatif etkilerken petrol ihraç eden ülkelerin GSYiH büyümesini pozitif etkilemektedir. Bu sonuç, petrol fiyatlarındaki değişimin ihracatçı ve ithalatçı ülkeler arasında gelir transferine neden olduğunu göstermektedir.

Hamilton (2003) çalışmasında petrol fiyatları ile GSYiH arasındaki negatif ilişkiden bahsetmektedir. Enerji fiyatları artınca üretim, istihdam ve reel ücret azalmaktadır. Hamilton (2003)'a göre petrol fiyatlarındaki değişim ekonomi üzerinde istatistiksel olarak güçlü bir etkiye sahiptir. Ayrıca beş büyük şokun; askeri mücadeleler, savaş, savaş beklentisi, psikolojik etki, para politikası yönetiminin petrol fiyatlarını değiştirerek makro ekonomiyi etkilediğini belirtmiştir.

Farzanegan ve Markwardt (2009) çalışmasında petrol fiyatlarında yaşanan şokun İran ekonomisindeki temel makro ekonomik değişkenler üzerindeki etkisini VAR analiziyle araştırmıştır. Analiz sonuçlarına göre petrol fiyatlarında yaşanan şok enflasyonu artıııken, sınai üretim üzerinde pozitif etkiye sahiptir. Ayrıca petrol fiyatlarındaki bu şoklar İran ekonomisinde Hollanda hastalığı sendromuna yol açmaktadır.

Iwayemi ve Fowowe (2010) 1985-2007 dönemi için petrol ihracatçısı gelişmekte olan ülke olan Nijerya'da petrol fiyatındaki değişikliğin makroekonomik değişkenler üzerindeki etkisini Granger nedensellik, etki tepki fonksiyonları, varyans ayrıştırma yöntemlerini kullanarak analiz etmiş ve petrol fiyatındaki değişikliğin Nijerya'nın çoğu makroekonomik değişkeni üzerinde büyük bir etkiye yol açmadığı sonucuna varmışlardır.

Öksüzler ve İpek (2011) çalışmasında petrol fiyatındaki değişikliklerin Türkiye'nin enflasyon ve büyüme değişkenleri üzerindeki etkilerini 1987-2010 dönemi için VAR modeliyle analiz etmiştir. Çalışmaya göre petrol fiyatlarındaki pozitif şokun büyüme ve enflasyonu pozitif etkilediği sonucuna ulaşılmıştır. Benzer bir çalışmada Özsağır vd.(2011) ham petrol fiyatlarındaki değişkenlikile Türkiye'nin GSYiH'si üzerine etkisini incelemek için 1987-2007 dönemini AngleGranger ve Johansen yöntemi kullanarak incelemiş ve petrol fiyatlarındaki değişimin Türkiye'nin GSYiH'si üzerinde pozitif etkisi olduğu sonucuna ulaşmışlardır.

Yaylalı ve Lebe (2012) çalışmasında ithal ham petrol fiyatlarının Türkiye'deki makroekonomik değişkenler üzerindeki etkilerini incelemek için 1986-2010 dönemini kapsayan çeyreklik verilere VAR analizi uygulamıştır. Para politikası değişkeni olarak; bankalar arası faiz oranı, para arzı değişkenlerinin yanı sıra, sanayi üretim endeksi, enflasyon oranı ve döviz kuru gibi temel makro ekonomik değişkenler ele alınmıştır. Ham petrol fiyatlarının özellikle para arzı üzerinde belirleyici olduğu ayrıca fiyatlar genel seviyesindeki değişimlerin de önemli bir nedeni olduğu sonucuna varmışlardır. Türkiye'de ham petrol ve benzin fiyatlarının sanayi üretimi üzerindeki etkilerini araştıran bir diğer çalışma Özdemir ve Akgül (2015) tarafından yapılmıştır. Bu çalışmada ham petrol ve benzin fiyatlarının sanayi üretimine etkisi MS-VAR analizi yardımıyla 2005-2014 dönemi için incelenmiştir. Özdemir ve Akgül (2015) çalışmasında dönemi iki farklı döneme ayırmış ve sanayi üretim endeksi ile petrol 
fiyatlarındaki değişimin bu dönemlerde farklı özellikler gösterdiği sonucuna varmışlardır. Illk dönemde benzin fiyatlarındaki oynaklığın sanayi üretimindeki oynaklığa göre daha fazla iken, ikinci dönemde durum tam tersini göstermiştir. Bu sonucu da kriz dönemlerinde krizin nedeni olarak ham petrol ve benzin fiyatlarındaki değişim ile açıklamışlardır. Büyüme dönemine geçildiğindeyse petrol ve benzin fiyatlarındaki oynaklık düşmekte ve ekonomide üretim artmaktadır.

Akıncı ve diğerleri (2012) 1980-2011 döneminde OPEC ve petrol ithalatçısı ülkelerin petrol fiyatlarıyla ekonomik büyüme arasındaki ilişkiyi panel eş bütünleşme ve nedensellik analizi ile çalışmışlardır. Çalışmaya göre OPEC ülkelerinde petrol fiyatı artışııın ekonomik büyümeyi artırdığı, ithalatçı ülkelerde ise ekonomik büyümeyi azalttığı sonucuna ulaşılmıştır. Akıncı ve diğerleri (2013) diğer çalışmasında aynı analizi zaman serileriyle yapmışlardır. Çalışmaya göre zaman serisi analizleri bazı petrol ithalatçısı ülkelerde petrol fiyatlarındaki artış ekonomik büyüme üzerinde pozitif ve anlamlı bir etkiye neden olduğu, Kiribati'de ise negatif ve anlamlı bir etkiye neden olduğu sonucuna ulaşmışlardır. Çalışma petrol fiyatı ile ekonomik büyüme arasındaki pozitif ilişkinin OPEC ülkelerinden sadece Birleşik Arap Emirlikleri için geçerli olduğu yönündedir.

Yardımcıoğlu ve Gülmez (2013) çalışmasında 10 OPEC ülkesinde 1970-2011 dönemi için petrol fiyatları ile ekonomik büyüme arasındaki ilişkiyi panel eş bütünleşme ve panel nedensellik ile analiz etmişler, uzun dönemde petrol fiyatları ile ekonomik büyüme arasında karşııklı olarak anlamlı ve pozitif bir ilişki olduğu sonucuna ulaşmışlardır.

Göçer ve Bulut (2015) çalışmalarında petrol fiyatlarındaki değişmenin Rusya ekonomisine etkilerini 1992-2014 dönemi için çoklu yapısal kırılmalı eş bütünleşme ve simetrik nedensellik testiyle analiz etmişlerdir. Çalışmaya göre petrol fiyatlarından ihracat, dış ticaret dengesi ve milli gelire doğru nedensellik olduğu sonucuna varmışlardır. Petrol fiyatlarındaki \%1'lik artışın Rusya'nın ihracatını \%1.01, dış ticaret dengesini $\% 0.27$, milli gelirini $\% 0.13$ oranında artırdığı sonucunu bulmuşlardır.

Yanar (2014) 1970'li yıllardan itibaren petrol fiyatlarındaki değişikliğin Orta Doğu ülkelerinin ekonomisine etkilerikonusundaki literatürçalışmasında petrol fiyatlarındaki artışın bu ülkelerde ekonomik büyümeyi artırdığından, petrol fiyatlarındaki azalışın ise ekonomik büyümeyi azalttığından bahsetmektedir.
Petrol gelirlerine bağımlılığı yüksek olan Orta Doğu ülkelerinde petrol fiyatı artışı döviz gelirini artırmakta buna karşın ulusal paraları değerlendiğinden petrol dışı sektörlerin rekabet gücünün azalmakta olduğunu belirtmektedir. Bu çerçevede Yanar (2014) söz konusu ülkelerin ekonomik çeşitliliğinin artırılması gerektiğini savunmaktadır.

\section{EKONOMETRIK ANALIZ}

\subsection{Veri Seti ve Matematiksel Model}

Çalışmada en çok petrol ithal eden 15 ülkede petrol fiyatlarındaki değişimin sanayi üretimi üzerindeki etkisi 2000-2015 dönemi için çeyreklik verilerle incelenmiştir. Analizde kullanılan sanayi üretim endeksi (IPI) ve ham petrol fiyatı (PO) verileri dolar cinsinden Dünya Bankası veritabanından temin edilmiştir. Üzerinde çalışılacak ekonometrik modelin matematiksel formu aşağıdaki gibi ifade edilmiştir;

$\mathrm{IPI}_{\mathrm{it}}=\alpha_{\mathrm{it}}+\beta_{\mathrm{it}} P O_{\mathrm{it}}+\mathrm{u}_{\mathrm{it}}$

Illk olarak sanayi üretim endeksi (IPI) ve ham petrol fiyatı $(P O)$ verilerine birim kök analizi uygulanmıştır. Daha sonra, sanayi üretim endeksi ve ham petrol fiyatları arasındaki uzun dönemli ilişkinin varlığını incelemek için Pedroni (1999), Kao (1999) ile sabit ve zaman etkilerini dikkate alan Johansen Fisher panel eşbütünleşme analizleri kullanılmıştır. Son olarak bu iki değişken arasındaki uzun dönemli ilişki hakkında yorum yapabilmek için Pedroni (2000) tarafından geliştirilen FMOLS (Full Modified Ordinary Least Square) ve yine Pedroni (2001) tarafından geliştirilen DOLS (Dynamic Ordinary Least Square) yöntemi uygulanmıştır.

\subsection{Panel Birim Kök Testleri}

Bu çalışmada ortak ve bireysel birim kök testleri olmak üzere petrole bağımlı 15 ülkenin sanayi üretim endeksi serilerine yedi farklı panel birim kök testi uygulanmıştır. (Levin et al. (2002), Breitung (2000), Im et al. (2003), ADF ve PP Fisher Tipi birim kök testleri, Maddala ve Wu (1999), Choi (2001) ve Hadri (1999)).

1. Nesil birim kök testleri olarak adlandırılan bu testlerde panel verilerinin olasılık değeri 0.10 olasılık değerinden küçük olduğu sürece panel veriler durağan kabul edilmektedir. Hatalar arasındaki otokorelasyon sorununu gideren uygun gecikme uzunluğu ise Schwarz bilgi kriterine göre seçilmiştir. Aşağıdaki Tablo 1'de en çok petrol ithal eden 15 ülkenin 2000Q1-201Q2 döneminde sanayi üretim endeksi (IPI) verilerine uygulanan 1. Nesil birim kök test istatistikleri ve 
olasılık değerleri sonuçları yer almaktadır. Tablo.1'e bakıldığında serilerin 7 birim kök testinden altısına göre sabitli, trendli modelde yüzde 1 anlamlılık düzeyinde durağan olduğu gözlemlenmiştir.

Ham petrol varil fiyatları her ülke için aynı olduğundan bu seriye birim kök testleri olan ADF, Dickey Fuller GLS, Phillips Perron, KPSS birim kök testleri uygulanmış ve sonuçları Tablo 2'de gösterilmiştir. Ham petrol varil fiyatının birinci farkında durağan olduğu gözlemlenmektedir.

Tablo 1: Panel Birim Kök Test Sonuçları

\begin{tabular}{|l|l|l|l|l|}
\hline \multirow{4}{*}{ Method } & \multicolumn{2}{|c|}{ Test istatistiği I(0) } & \multicolumn{2}{c|}{ Test İstatistiği I(1) } \\
\cline { 2 - 6 } & Trendsiz & Trendli & Trendsiz & Trendli \\
\hline Levin et al. t* & $0.81(0.79)$ & $-3.07(0.00)^{* * *}$ & $-13.05(0.00)^{* * * *}$ & $-12.10(0.00)^{* * *}$ \\
\hline Breitung t-stat & - & $-0.35(0.36)$ & - & $-12.25(0.00)^{* * *}$ \\
\hline Im et al. W-stat & $0.50(0.69)$ & $-4.16(0.00)^{* * *}$ & $-17.42(0.00)^{* * *}$ & $-16.25(0.00)^{* * *}$ \\
\hline ADF - Fisher Chi-square & $30.95(0.41)$ & $71.38(0.00)^{* * *}$ & $324.52(0.00)^{* * *}$ & $274.25(0.00)^{* * *}$ \\
\hline PP - Fisher Chi-square & $18.87(0.94)$ & $55.60(0.00)^{* * *}$ & $497.79(0.00)^{* * *}$ & $399.49(0.00)^{* * *}$ \\
\hline Hadri Z-stat & $20.37(0.00)^{* * *}$ & $11.71(0.00)^{* * *}$ & $0.61(0.26)$ & $1.53(0.06)^{* *}$ \\
\hline Heteroscedastic Consistent Z-stat & $15.93(0.00)^{* * *}$ & $6.19(0.00)^{* * *}$ & $-0.23(0.59)$ & $4.01(0.00)^{* * *}$ \\
\hline
\end{tabular}

Not: Olasılık değerleri parantez içinde yer almaktadır. ${ }^{*}{ }^{* *}$ ve ${ }^{* * *}$ sırasıyla istatistiksel olarak $10 \%, 5 \%$ ve $1 \%$ anlamlııı düzeylerine karşılık gelmektedir.

Tablo 2: Ham Petrol Varil Fiyatlarına Ait Birim Kök Test Sonuçları

\begin{tabular}{|l|l|l|l|l|}
\hline \multirow{4}{*}{ Method } & \multicolumn{2}{|c|}{ Test İstatistiği I(0) } & \multicolumn{2}{c|}{ Test İstatistiği I(1) } \\
\cline { 2 - 5 } & \multicolumn{2}{|c|}{ Sabitli } & \multicolumn{1}{|c|}{ Sabitli-Trendli } & \multicolumn{2}{c|}{ Sabitli } & \multicolumn{1}{|c|}{ Sabitli-Trendli } \\
\hline Augmented D-F & $-1.50(0.52)$ & $-3.39(0.06)^{*}$ & $-6.63(0.00)^{* * *}$ & $-6.64(0.00)^{* * *}$ \\
\hline Dickey-Fuller GLS(ERS) & -0.97 & $-3.36^{* *}$ & $-6.69^{* * *}$ & $-6.69^{* * *}$ \\
& {$[-2.60$} & {$[-3.73$} & {$[-2.60$} & {$[-3.73$} \\
& -1.94 & -3.15 & -1.94 & -3.16 \\
& $-1.61]$ & $-2.86]$ & $-1.61]$ & $-2.86]$ \\
\hline Phillips-Perron & $-1.61(0.46)$ & $-2.06(0.55)$ & $-5.51(0.00)^{* * *}$ & $-5.55(0.00)^{* * *}$ \\
\hline KPSS & 0.81 & $0.11^{* *}$ & $0.18^{* * *}$ & $0.10^{* * *}$ \\
& {$[0.73$} & {$[0.21$} & {$[0.73$} & {$[0.21$} \\
& 0.46 & 0.14 & 0.46 & 0.14 \\
& $0.34)$ & $0.11]$ & $0.34]$ & $0.11]$ \\
\hline
\end{tabular}

Not: Olasılık değerleri parantez içinde yer almaktadır. Test istatistikleri köşeli parantez içinde yer almaktadır. ${ }^{*}{ }^{* *}$ ve ${ }^{* * *}$ sırasıyla istatistiksel olarak $10 \%, 5 \%$ ve $1 \%$ anlamlılık düzeylerine karşılık gelmektedir.

\subsection{Panel Eşbütünleşme Testleri}

Uzun dönemli bir iliş̧inin olup olmadığı Pedroni, Kao ve Johansen Fisher eşbütünleşme testi yardımıyla incelenmiştir. Pedroni 1997, 1999, 2000 ve 2004 yıllarında eşbütünleşme analizlerinde hetorejenliğe izin veren birkaç test önerisi ileri sürmüştür (Asteriou, 2007:373). Pedroni'nin geliştirdiği bu test hem kısa dönemde hem de uzun dönemde kointegre olmuş vektörler arasında heterojenliğe izin verir. Kao (1999) eşbütünleşme testi de kointegrasyon vektörlerinin arasındaki heterojenliği kabul eder ancak asimtotik denklik nedeniyle bağımsız değişkenlerin endojenliği kuralı ihlal edilir. Pedroni (1999) eşbütünleşme regresyon denklemi aşağıdaki gibi regresyon denklemi ile temsil edilir; 


$$
y_{i, t}=\alpha_{i}+\delta_{i}+\beta_{1 i} x_{1, t}+\beta_{2 i} x_{2 i, t}+\cdots+\beta_{M i} x_{M i, t}+e_{i, t} \quad ; t=1, \ldots, T=1, \ldots, N, m=1, \ldots, M
$$

Denklem 2'de yer alan T; gözlem sayısını, N; panelde yer alan birey sayısını, $M$; regresyon değişken sayısını temsil eder. Panelde $\mathrm{N}$ tane birey olduğundan, her $\mathrm{M}$ tane regresöre $\mathrm{N}$ farklı denklem olacaktır. $\beta_{1 i}+\beta_{2 i}+\cdots+\beta_{M i}$ ise panelde yer alan bireyler arasındaki farklııkları temsil eden katsayılardır. $\alpha_{i}$ parametresi ise parametre bireyleri arasındaki farklılığa izin veren sabit etkiler parametresidir. Bu parametreye ek olarak panelde bireyler arasında deterministik trend söz konusu ise denkleme $\delta_{i} t$ parametresi de eklenir.

Sanayi üretim endeksi ve ham petrol varil fiyatı arasında uzun dönemli ilişkiyi araştırdığımız Pedroni eşbütünleşme testine göre " $H_{0}$ : Seriler arasında eşbütünleşme yoktur" hipotezi reddedilmiştir. Tablo 3'deki test sonuçlarından panel istatistiklerinin dördü de \%1 anlamlılık seviyesinde istatistiksel olarak anlamlıdır. Grup istatistiklerinden üçü de yine \%1 anlamlılık seviyesinde istatistiksel olarak anlamlıdır. Pedroni Eşbütünleşme testi sonuçları genel olarak değerlendirildiğinde hem panel hem de grup istatistiklerini oluşturan yedi teste göre seriler arasında kuvvetli bir eşbütünleşme ilişkisini göstermektedir (Baltagi, 2000).

Tablo 3: Panel Eşbütünleşme Testi Sonuçları ve Değerlendirilmesi

\begin{tabular}{|c|c|c|c|c|}
\hline \multicolumn{5}{|c|}{$\mathrm{IPI}_{\mathrm{it}}=\alpha_{\mathrm{it}}+\beta_{\mathrm{it}} P O_{\mathrm{it}}+\mathrm{u}_{\mathrm{it}}$} \\
\hline \multicolumn{5}{|c|}{ Pedroni's Panel Eşbütünleşme Test Sonuçları } \\
\hline \multicolumn{5}{|l|}{ (Boyut İçinde) } \\
\hline & t- istatistiği & $\begin{array}{l}\text { Olasılık } \\
\text { Değeri }\end{array}$ & $\begin{array}{l}\text { Ağırlıklandırıımış } \\
\text { t-istatistiği }\end{array}$ & $\begin{array}{l}\text { Olasılık } \\
\text { Değeri }\end{array}$ \\
\hline Panel v-İstatistiği & 12.88 & $0.00^{* * *}$ & 3.67 & $0.00 * * *$ \\
\hline Panel rho-İstatistiği & -11.45 & $0.00^{* * *}$ & -4.38 & $0.00^{* * *}$ \\
\hline Panel PP-İstatistiği & -9.05 & $0.00^{* * * *}$ & -4.07 & $0.00^{* * *}$ \\
\hline Panel ADF-İstatistiği & -2.18 & $0.01^{* * * *}$ & -2.22 & $0.01^{* * *}$ \\
\hline \multicolumn{5}{|l|}{ (Boyutlar Arasında) } \\
\hline & t- İstatistiği & \multicolumn{3}{|l|}{ Olasılık Değeri } \\
\hline Group rho-İstatistiği & -3.82 & \multicolumn{3}{|l|}{$0.00^{* * *}$} \\
\hline Group PP-İstatistiği & -4.19 & \multicolumn{3}{|l|}{$0.00^{* * *}$} \\
\hline Group ADF-İstatistiği & -2.21 & \multicolumn{3}{|l|}{$0.01^{* * *}$} \\
\hline \multicolumn{5}{|c|}{ Kao's Panel Eşbütünleşme Test Sonuçları } \\
\hline & & & t-İstatistiği & Olasılık Değeri \\
\hline ADF & & & 2.22 & $0.01^{* * *}$ \\
\hline Artık Varyans & & & 40.60 & \\
\hline HAC Varyans & & & 66.00 & \\
\hline \multicolumn{5}{|c|}{ Johansen Fisher's Panel Eşbütünleşme Test Sonuçları } \\
\hline Hesaplanan CE(s) sayıları & $\begin{array}{l}\text { Fisher İstastiği.* } \\
\text { (fromtrace test) }\end{array}$ & Olasılık Değeri & $\begin{array}{l}\text { Fisher İstatistiği.* } \\
\text { ( f r o m max-ei gen } \\
\text { test) }\end{array}$ & Olasılık Değeri \\
\hline Hiçbiri & 114.0 & $0.00^{* * *}$ & 108.4 & $0.00^{* * *}$ \\
\hline En fazla 1 & 48.78 & $0.01^{* * *}$ & 48.78 & $0.01^{* * *}$ \\
\hline
\end{tabular}

Not: ${ }^{*}{ }^{* *}$ ve ${ }^{* * *}$ sırasıyla $10 \%, 5 \%$ and $1 \%$ anlamlılık düzeylerini temsil etmektedir. Uygun gecikme uzunluğu Schwarz bilgi kriterine göre seçilmiştir. 
Yine Tablo 3'de yer alan Kao eşbütünleşme test sonuçlarına göre " $H_{0:}$ Seriler arasında eşbütünleşme yoktur" hipotezi reddedilmemiştir. Johansen Fisher eşbütünleşme testine göreyse " $H_{0}$ : Seriler arasında eşbütünleşme yoktur" hipotezi reddedilmiş alternatif hipotez olan " $H_{1}$ : Seriler arasında eşbütünleşme vardır" hipotezi kabul edilmiştir. Böylece en çok petrol ithal eden 15 ülkede sanayi üretim endeksi ve ham petrol varil fiyatı arasında uzun dönemli ilişki olduğu sonucuna ulaşılmıştır.

\subsection{Düzenlenmiş/Geliştirilmiş En Küçük Kareler Yöntemi (Fully Modified Ordinary Least Squares-FMOLS) ve Dinamik En Küçük Kareler Yöntemi (Dynamic Ordinary Least Square-DOLS) Katsayıları Bulguları ve Değerlendirilmesi}

Eşbütünleşme testleri uygulandıktan sonra petrol fiyatları (PO) ve sanayi üretimi endeksi (IPI) arasındaki uzun dönemli ilişkiyle ilgili çıkarımda bulunabilmek için Pedroni (2000) tarafından geliştirilen, kısa dönemde büyük ölçüde heterojenliğe izin veren asimtotik dağılıma sahip nihai sapmasız katsayıyı hesaplamak amacıyla Düzenlenmiş/Geliştirilmiş En Küçük Kareler Yöntemi (Fully Modified Ordinary Least Squares-FMOLS) ve Dinamik En Küçük Kareler Yöntemi (Dynamic Ordinary Least Square-DOLS) uygulanmıştır.

FMOLS yönteminde dinamik panelde değişkenler arasındaki ilişki araştııılırken; sabit terim, hata terimi ve değişkenler arasındaki heterojenliğe izin veren korelasyonun derecesi dikkate alını. Bu amaçla geliştirilen FMOLS yöntemi aşağıdaki panel regresyon modeline dayanır;

$y_{i t}=\alpha_{i}+\beta x_{i t}+\mu_{i t}$

$x_{i t}=x_{i t-1}+\varepsilon_{i t}$

Denklemde (3)'te yer alan $y_{i t}$ bağımlı değişken, $x_{i t}$ bağımsız değişken ve $\alpha_{i}$ sabit etkileri temsil eder. Ayrıca paneli oluşturan kesitler asimtotik dağılıma sahiptir. $y_{i t}$ ile $x_{i t}$ arasında uzun dönemli eşbütünleşme ilişkisini gösteren denklem (3)'te $\beta$ ile temsil edilen uzun dönem eşbütünleşme katsayısı tahmin edilecektir (Pedroni, 2015:110). Pedroni (2000) tarafından geliştirilen FMOLS yöntemi uygulandığında bu katsayı 0.47 olarak tahmin edilmiştir. Tablo 4'te gösterilen sonuç pozitif ve istatistiksel olarak \%1 anlamlılık düzeyinde anlamlıdır. Öyleyse petrole bağımlı olan bu 15 ülkenin genelinde ham petrol varil fiyatında yaşanan \%1 oranındaki değişim, sanayi üretim endeksi üzerinde uzun dönemde yaklaşık \%0.47 değişmeye neden olacaktır.
Tablo 4: FMOLS ve DOLS ile Eşbütünleşme Katsayıları Bulguları ve Değerlendirilmesi

\begin{tabular}{|ll|}
\hline $\mathbf{I P I}_{\text {it }}=\boldsymbol{\alpha}_{\text {it }}+\boldsymbol{\beta}_{\text {it }} \boldsymbol{P O _ { i t }}+\mathbf{u}_{\text {it }}$ \\
\hline FMOLS & \\
\hline Katsayı & t-İstatistiği \\
\hline $0.4792(0.00)$ & 10.2069 \\
\hline DOLS & \\
\hline $0.4756(0.00)$ & 9.8165 \\
\hline
\end{tabular}

Not: ${ }^{*},{ }^{* *}$ ve ${ }^{* * *}$ sırasiyla $10 \%, 5 \%$ and $1 \%$ anlamlılık düzeylerini temsil etmektedir.

Petrol fiyatları ile sanayi üretim endeksi arasındaki ilişkinin nihai sapmasız katsayılarını tahmin etmek üzere uygulanacak diğer bir yöntem Pedroni (2001) tarafından geliştirilen DOLS (Dynamic Ordinary Least Square) yöntemidir. DOLS yöntemi küçük örneklemlerde daha tutarlı sonuç vermektedir. (Breitung, 2005). Bu nedenle çalışmada uzun dönem eşbütünleşme katsayıları tahmin edilirken DOLS yöntemi de kullanılmıştır. DOLS grup ortalama panel tahmincisi yönteminde kullanılan regresyon denklemi ise aşağıdaki gibidir;

$s_{i t}=\alpha_{i}+\beta_{i} p_{i t}+\sum_{k=-K i}^{K i} \gamma_{i k} \Delta p_{i t-k}+\mu_{i t}^{*}$

Yukarıdaki denklem (5)'ten elde edilen grup ortalama panel DOLS tahmincisi aşağıdaki denklem ile temsil edilir;

$\hat{\beta}_{G D}^{*}=N^{-1} \sum_{i=1}^{N} \hat{\beta}_{D, i}^{*}$

Yukarıdaki denklem (6)'te yer alan $\hat{\beta}_{G D}^{*}$ her bir yatay kesit için DOLS tahmininden elde edilen eşbütünleşme katsayısını temsil etmektedir. Grup ortalama panel DOLS tahmincilerine ait t-istatistikleri ise aşağıdaki denklem (7) ile hesaplanmaktadır;

$t_{\widehat{\beta}_{D, i}^{*}}=\left(\hat{\beta}_{D, i}^{*}-\beta_{0}\right)\left(\hat{\sigma}_{i}^{-2} \sum_{t=1}^{T}\left(p_{i t}-\bar{p}_{i}\right)^{2}\right)^{1 / 2}$

Pedroni (2001) tarafından geliştirilen DOLS yöntemi uygulandığında bu katsayı da 0.47 olarak tahmin edilmiştir. Tahmin edilen sonuç pozitif ve istatistiksel olarak \%1 anlamlılık düzeyinde anlamlıdır. Öyleyse FMOLS test sonuçlarında olduğu gibi petrole bağımlı olan bu 15 ülkenin genelinde ham petrol varil fiyatında yaşanan \%1 oranındaki değişim, sanayi üretim endeksi üzerinde uzun dönemde yaklaşık \%0.47 değişmeye neden olacaktır. Hem FMOLS hem de DOLS katsayılarının pozitif çıkması, uzun dönemde 
petrol fiyatları ile sanayi üretimi arasında pozitif ilişki olduğunu göstermektedir. Petrol ithalatçısı bu ülkelerin ham petrolü kullanarak ürettikleri mamulleri dış pazara daha yüksek fiyatlara sattığı sonucuna ulaşabiliriz.

\section{SONUÇ}

Enerji iktisadi büyümenin temel kaynağıdır. Petrol ise enerji kaynakları içinde en çok kullanılan üretim girdilerinden biridir. Petrol üretiminin sınırlı olması buna karşın talebinin artış trendinde olması bir yandan petrol gibi yenilenemez enerji kaynaklarının tükenmesine diğer yandan petrol fiyatlarının artmasına yol açacaktır. Yenilenemez enerji kaynağı olan petrol fiyatının artması petrole bağımlıı̆ı yüksek ülkeleri hem sanayi üretimlerini hem de talep, enflasyon ve iktisadi büyümelerini etkilemektedir. Buna göre petrol fiyatlarının artması petrole bağımlı ülkelerin sanayi üretimlerini etkilemekteveüretim maliyetlerini artırarak fiyatlar genel seviyesinin yükselmesine yol açmaktadır. Fiyat artışı tüketicinin refah düzeyini düşürmekte ve talebini azaltarak ekonomik durgunluğa yol açmaktadır. Petrol girdisine bağımlılığı yüksek ülkelerin petrol fiyat değişikliklerine karşı makroekonomik kırılganlığı yüksektir. Bu nedenle petrol ithal eden ülkelerin petrol fiyatı değişikliklerine duyarlıı̆ını en aza indirgemek gerekir. Bunun için yenilenemez enerji kaynakları yerine rüzgar, güneş, hidrolik enerji gibi yenilenebilir enerji kaynaklarının geliştirilmesi ve üretime absorbe edilmesi gerekmektedir. Ayrıca petrol tüketiminin tasarruflu kullanımı için teknoloji gelişimi sağlanmalıdır. Yenilenebilir enerji kaynaklarının üretim sürecinde yoğun olarak kullanımı çabaları bir taraftan petrole dış bağımlıı̆ı̆ azalmasına diğer taraftan girdi maliyetlerinin azalmasına yol açarak üretim ve refahın artması dolayısıyla büyümenin artması bakımından önem arz etmektedir.

Literatüre bakıldığında petrol fiyatlarındaki değişimin ekonomiye etkileri büyüme, enflasyon ve sanayi üretimi gibi değişkenler üzerinden incelendiği görülmektedir. Bu çalışmada da en çok petrol ithal eden on beş ülkede petrol fiyatlarındaki değişimin sanayi üretimi arasındaki uzun dönemli ilişkinin varlığı ortaya koyulmuştur. Teorik olarak petrol fiyatlarındaki artış ile sanayi üretimi arasında negatif yönlü bir ilişkinin olması beklenmektedir. Nitekim sanayi üretiminde önemli bir üretim girdisi olan ham petrol fiyatındaki artış, firmalara önemli bir maliyet yüklemekte; bu durum ise üretim verimliliğinin düşmesiyle üretim çıktı düzeyini azaltmaktadır. Petrol fiyatlarındaki artışın ekonomik büyüme üzerindeki azaltıcı etkisinin incelendiği çalışmamızda petrol ithalatçısı on beş ülkenin sanayi üretimi ile ham petrol fiyatı arasındaki ilişkinin pozitif yönlü olduğu sonucuna varılmıştır. Bu durum sanayileşme düzeyleri yüksek olan bu ülkelerin ham petrolü işleyerek ürettikleri mamulleri daha karlı bir şekilde dış ülkelere pazarladıkları şeklinde yorumlanabilir.

\section{SON NOTLAR}

'Petrole bağımlı ülkeler kapsamında incelenen 15 ülke; ABD, Japonya, Çin, Almanya, Güney Kore, Hindistan, Fransa, İspanya, İtalya, Tayvan, Singapur, Hollanda, Belçika, Türkiye ve Tayland şeklindedir. 


\section{KAYNAKLAR}

Abeysinghe, T. (2001) “Estimation of Direct and Indirect Impact of Oil Price on Growth", Economics Letters, 73:147-153.

Akıncı, M. vd. (2012) "Petrol Fiyatları ile Ekonomik Büyüme Arasındaki İlişki: OPEC ve Petrol İthalatçısı Ülkeler İçin Panel Veri Analizi", Uludağ Üniversitesi iiBF Dergisi, 31(2):1-17.

Akıncı, M. vd. (2013) "Petrol Fiyatları ile Ekonomik Büyüme Arasındaki İlişki: OPEC ve Petrol İthalatçısı Ülkeler İçin Zaman Serisi Analizi", Atatürk Üniversitesi Sosyal Bilimler Enstitüsü Dergisi, 17(1):349-361.

Asteriou, D. ve Hall S.G. (2007) Applied Econometrics: A Modern Approach Using Eviews and Microfit Revisited Edition, PalgraveMacmillan, Newyork, ss.373.

Baltagi, B.H. vd. (2000) "Nonstationary Panels, Cointegration in Panels: A Survey", Center for Policy Research Working Paper No.16, http://www. maxwell.syr.edu/uploadedFiles/cpr/publications/ working_papers/wp16.pdf (26.04.2016)

Bayraç, H.N. (2011) "Küresel Enerji Politikaları ve Türkiye: Petrol ve Doğalgaz Kaynakları Açısından Bir Karşılaştırma", Eskişehir Osmangazi Üniversitesi Sosyal Bilimler Dergisi, 10(1):115-142.

Breitung, J. (2000) "The Local Power of Some Unit Root Tests for Panel Data", http://edoc.hu-berlin. de/series/sfb-373-papers/1999-69/PDF/69.pdf (18.05.2016)

Breitung, J. (2005) "A Parametric Approach to The Estimation of Cointegration Vectors in Panel Data", Econometric Reviews, 24(2), 151-173.

Burbidge, J. ve Harrison A. (1984) "Testing for the Effects of Oil-Price Rises Using Vector Autoregressions", International Economic Review, 25(2):459-484.

Choi, I. (2001), “Unit Root Tests for Panel Data”, Journal of International Money and Finance, 20: 249-272.

Cunado, Juncal ve Gracia F.P.D. (2003) "Do Oil Price Shocks Matter? Evidence for Some European Countries", Energy Economics, 25:137-154.

Cunado, J. ve Gracia F. P.D. (2004) “Oil Prices, Economic Activity and Inflation: Evidence for Some Asian Countries", The Quarterly Review of Economics and Finance, 45(1):65-83.

Farzanegan, M. R. ve Markwardt G. (2009) "The Effect of Oil Price Shocks on The Iranian Economy", Energy Economics, 31:134-151.

Ferderer, J.P. (1996) "Oil Price Volatility and The Macroeconomy", Journal of Macroeconomics, 18(1):1-26.
Göçer, İ ve Bulut Ş. (2015)“Petrol Fiyatlarındaki Değişimlerin Rusya Ekonomisine Etkileri: Çoklu yapısal Kırılmalı Eşbütünleşme ve Simetrik nedensellik Analizi", Çankırı Karatekin Üniversitesi IïBF Dergisi, 1-28.

Güler, S. ve Nalın H.T. (2013) "Petrol fiyatlarının IMKB Endeksleri Üzerindeki Etkisi", Ekonomik ve Sosyal Araştırmalar Dergisi, 9(2):79-97.

Hadri K. (1999) "Testing for Stationarity in Heterogeneous Panel Data", Econometrics Journal, 3:148-161.

Hamilton, J.D. (1983) "Oil and the Macroeconomy since World War II", Journal of Political Economy, 91(2):228248.

Hamilton, J.D. (1988) "Are the Macroeconomic Effects of Oil-Price Changes Symmetric? : A Comment," Carnegie-Rochester Conference Series on Public Policy, Elsevier, 28(1):369-378.

Hamliton, J.D. (1996) "This is What Happened to the Oil Price-Macroeconomy Relationship", Journal of Monetary Economics, 38:215-220.

Hamilton, J.D. (2003), "What is An Oil Shock?" Journal of Econometrics, 113:363-398.

Hooker, M.A. (1996) "What Happened to the Oil Price-Macroeconomy Relationship?", Journal of Monetary Economics, 39(2):215-220.

Im, K.S., M.H. Pesaran veY. Shin (2003) "Testing for Unit Roots in Heterogeneous Panels", Journal of Econometrics, 115:53-74.

Iwayemi, A. ve Fowowe B. (2011) "Impact of Oil Price Shocks on Selected Macroeconomic Variables in Nigeria", Energy Policy, 39:603-612.

Kao C. (1999) "Spurious Regression and Residual-Based Tests for Cointegration in Panel Data", Journal of Econometrics, 90:1-44.

Lee, K. ve Ni S. (2002), "On the Dynamic Effects of Oil Price Shocks: A Study Using Industry Level Data", Journal of Monetary Economics, 49:823-852.

Levin, A. vd. (2002), "Unit Root Tests in Panel Data: Asymptotic and Finite Sample Properties", Journal of Econometrics, 108:1-24.

Maddala, G.S. ve ShaowenWu (1999), "Comparative Study of Unit Root Tests With Panel Data and a New Simple Test", Oxford Bulletin of Economics and Statistics, Special Issue, 61: 631-652.

Mork, K.A. (1989) "Oil and the Macroeconomy When Prices Go Up and Down: An Extension of Hamilton's Results", Journal of Political Economy, 91:740-744. 
Öksüzler, O. ve İpek E. (2011) “Dünya Petrol Fiyatlarındaki Değişimin Büyüme ve Enflasyon Üzerindeki Etkisi: Türkiye Örneği", ZKÜ Sosyal Bilimler Dergisi, 7(4):15-34.

Özdemir, A. ve Yüksel F. (2006) "Türkiye'de Enerji Sektörünün İleri ve Geri Bağlantı Etkileri", Yönetim ve Ekonomi Dergisi, 3(2):1-18.

Özdemir, S. ve Akgül I. (2015) “Ham Petrol ve Benzin fiyatlarının Sanayi Üretimine Etkisi: MS-VAR Modelleri ile Analizi", Ege Akademik Bakış, 15(3):367-378.

Özsağır, A. vd. (2011) “Ham Petrol Fiyatlarındaki Volatilitenin GSYiH Büyümesi Üzerindeki Etkileri: Türkiye Örneği", Yönetim ve Ekonomi Dergisi, 1(18):19-28.

Pedroni P. (1999) "Critical Values for Cointegration Tests in Heterogeneous Panels with Multiple Regressors", Oxford Bulletin of Economics and Statistics, 1999;61:653-70.

Pedroni, P. (2000) "Fully-Modified OLS forHeterogeneousCointegratedPanels", Advances in Econometrics, 15:93-130.

Pedroni P. (2001) "Purchasing Power Parity Tests in Cointegrated Panels", The Review of Economics and Statistics, 83(4):727-731.

Pedroni P. (2015)“Fully Modified OLS for Heterogeneous Cointegrated Panels' in Nonstationary Panels, Panel
Cointegration, and Dynamic Panels". Online Basım: 08 Mar 2015; 93-130, http://dx.doi.org/10.1016/ S0731-9053(00)15004-2

Selim, C. (2011)“Enerji Teknolojilerindeki Anlayış Model Değişimi ve Hızlı İklim Değişikliği", Journal of Yaşar University, 21(6):3515-3522.

Şanlı, F.B ve Tuna K. (2014) “Türkiye'de Petrol Tüketimi ile Ekonomik Büyüme Arasındaki İlişkinin Analizi", Maliye Finans Yazıları, 108:47-64.

Yanar, R. ve Kerimoğlu G. (2011) "Türkiye'de Enerji Tüketimi, Ekonomik Büyüme ve Cari Açık Ilişkisi", Ekonomi Bilimleri Dergisi, 3(2):191-201.

Yanar R. (2014) "Petrol fiyatlarındaki Düşüş ve Ortadoğu Ekonomilerine Etkileri", Orsam Rapor, 194:1-20.

Yardımcıoğlu, F. Ve Gülmez A. (2013) “OPEC Ülkelerinde Hollanda Hastalığı: Petrol Fiyatları ve Ekonomik Büyüme İlişkisinin Ekonometrik Bir Analizi", Sosyo Ekonomi Dergisi, 1:117-140.

Yaylalı, M. ve Lebe F. (2012) “ithal Ham Petrol Fiyatlarının Türkiye'deki Makroekonomik Aktiviteler Üzerindeki Etkisi", Marmara Üniversitesi IiBF Dergisi, 32(1):43-68.

Zivot, E. Ve Andrews D.W.K. (1992) "Further Evidence on the Great Crash, the Oil Price Shock and the UnitRoot Hypothesis", Journal of Business\&Economic Statistics, 10(3):24-44. 